Original Article

\title{
Perbedaan Penggunaan Komposter An-Aerob dan Aerob Terhadap Laju Proses Pengomposan Sampah Organik
}

\section{Differences in the use of an-aerobic and aerobic composters on the rate of organic waste composting}

\author{
Suharno*, Slamet Wardoyo, Taufik Anwar \\ Jurusan Kesehatan Lingkungan, Poltekkes Kemenkes Pontianak, Indonesia
}

(suharnopontianak@gmail.com,085787549486)

\begin{abstract}
ABSTRAK
Masalah sampah pasar tradisional sebenarnya tidak terlalu susah, namun juga tidak sederhana, karena memiliki karakteristik yang sedikit berbeda dengan sampah dari perumahan. Komposisi sampah pasar tradisional lebih dominan sampah organik yang dapat di daur ulang menjadi kompos atau pupuk organik. Agar proses pengomposan dapat berlangsung lebih cepat diperlukan alat biakan berupa komposter dan menambahkan aktivator atau biang kompos. Tujuan penelitian ini yaitu enganalisis perbedaan penggunaan Komposter An-aerob dengan Komposter Aerob terhadap laju proses pengomposan sampah organik. Penelitian menggunakan metode eksperimen semu (quasi experiment), antara perlakuan (komposter Aerob) dengan kontrol (komposter An-aerob). Hasil menunjukkan kecepatan waktu pematangan kompos pada parameter perubahan warna bahan dan bau bahan kompos dengan komposter anaerob rata-rata kecepatan kematangan kompos sebesar 10,22 hari, sedangkan dengan komposter aerob rata-rata kecepatan kematangan kompos sebesar 9,89 hari. Berdasarkan uji statistik Wilcoxon Signed Rank Test dengan $\alpha$ 5\%, untuk parameter warna diperoleh tingkat signifikansi ( $\mathrm{p}$ value) sebesar 0,006 , sedangkan berdasarkan parameter bau diperoleh tingkat signifikansi (p value) sebesar 0,003 . Dengan demikian ada perbedaan yang bermakna antara proses pengomposan dengan menggunakan komposter anaerob dengan komposter aerob.
\end{abstract}

Kata kunci : Komposter, An-aerob dan Aerob, Sampah Organik

\section{ABSTRACT}

The problem of traditional market waste is complicated and not simple because it has slightly different characteristics from waste from the housing. Standard market waste is more dominant in organic waste, recycled into compost or organic fertilizer. For the composting process to take place more quickly, a culture tool in the form of a composter is needed and adding an activator or compost starter. The purpose of this study is to analyze the difference between the use of an An-Aerobic Composter and an Aerobic Composter on the rate of the composting process of organic waste. The study used a quasi-experimental method (quasi-experimental) between treatment (Aerobic composter) and control (an Anaerobic composter). The results show the speed of compost maturation time on the parameters of changes in color and odor of compost material with an anaerobic composter. The average maturity speed of compost is 10.22 days, while with an aerobic composter, the average rate of compost maturity is 9.89 days. Based on the statistical test Wilcoxon Signed Rank Test with 5\%, the color parameter obtained a significance level (p-value) of 0.006, while based on the odor parameter, a significance level (p-value) of 0.003. Thus, there is a significant difference between the composting process using an anaerobic composter and an aerobic composter.

Keywords : Composter, Anaerobic and Aerobic, Organic Waste https://doi.org/10.33860/jik.v15i3.527 


\section{PENDAHULUAN}

Pasar sebagai tempat bertemunya pembeli dan penjual untuk menjual dan membeli barang atau jasa, yang merupakan suatu tempat pada waktu tertentu para penjual dan pembeli dapat bertemu guna melakukan transaksi jual beli barang. Barang-barang yang diperjual belikan adalah barang yang berupa barang kebutuhan pokok . Dari hasil aktivitas di pasar akan diperoleh hasil buangan yang berupa sampah. ${ }^{1}$ Penanganan sampah yang tidak baik akan menimbulkan dampak yang luas, tidak saja bagi lingkungan, tetapi juga berdampak buruk bagi perekonomian dan sosial. ${ }^{2}$ Penanganan masalah sampah pasar tradisional sebenarnya tidak terlalu susah, namun juga tidak sederhana. Sampah pasar tradisional memiliki karakteristik yang sedikit berbeda dengan sampah dari perumahan. Komposisi sampah pasar tradisional lebih dominan sampah organik dari pada sampah anorganik. ${ }^{3,4}$

Dari pengamatan awal terhadap penanganan samah di pasar Kota Pontianak, umumnya pedagang membuang sampah disekitar tempat jualan dan atau pojokan los pasar. Sampah yang dibuang dan disimpan disekitar tempat jualan, pada siang dan atau sore hari diangkut oleh petugas kebersihan dan dibuang ke tempat pengumpul sampah sementara (TPS) sebelum diangkut ke tempat pembuangan akhir (TPA) dengan mnggunakan gerobak sampah.

Sampah dari pasar yang ada di Kota Pontianak berkisar sebesar $5-8$ ton per hari. Dan diperkirakan 60\% - 80\% merupakan sampah organik. Maka jika sampah organik ini diolah menjadi kompos maka bisa dihasilkan kurang lebih 1,5 s/d 3 ton kompos/hari atau kurang lebih $45 \mathrm{~s} / \mathrm{d} 75$ ton sebulan. Mengolah sampah pasar tradisional menjadi kompos dan pupuk organik merupakan salah satu alternatif pengolahan sampah yang mudah, murah, dan cepat. ${ }^{1,5}$

Kompos sebagai salah satu pupuk organik dari proses pembusukan sisa-sisa bahan organik (sampah tanaman maupun kotoran hewan). Proses pengomposan merupakan suatu proses di mana bahan organik mengalami penguraian secara biologis, khususnya oleh mikroba-mikroba yang memanfaatkan bahan organik sebagai sumber energi, yang dapat berlangsung secara aerobik dan anaerobik yang saling menunjang pada kondisi lingkungan tertentu. Pembuatan kompos adalah mengatur dan mengontrol proses alami tersebut agar kompos dapat terbentuk lebih cepat. Proses pengomposan sampah secara tradisional berlangsung dalam waktu lama, berkisar $1-2$ bulan, rata-rata 1,5 bulan..$^{6-9}$ Agar proses pengomposan dapat berlangsung lebih cepat perlu perlakuan dengan menggunakan alat biakan berupa komposter dan menambahkan aktivator atau biang kompos. ${ }^{7,9}$

Komposter yang selama ini dipergunakan berupa komposter anaerob, yang hanya mengandalkan suplai udara secara alami. Adapun waktu yang diperlukan dalam pembuatan kompos dengan menggunakan komposter anaerob sekitar $2 \mathrm{~s} / \mathrm{d} 3$ minggu. Sehingga perlu adanya pengembangan alat komposter yang dapat menyuplai udara dalam proses penguraian, sehingga proses berlangsung secara Aerob.

\section{METODE PENELITIAN}

Penelitian ini dilakukan dengan metode eksperimen semu (quasi experiment), yaitu penelitian yang mendekati percobaan sungguhan, antara perlakuan (komposter Aerob) dengan kontrol (komposter Anaerob) semua variabel yang relevan (Notoatmodjo, 2005). Objek adalah sampah organik yang ada di Pasar Tradisional Kota Pontianak. Sampel yang digunakan dalam penelitian ini adalah sampah organik yang didapat dari Pasar Puring Siantan dan Pasar Flamboyan Kota Pontianak, dengan jumlah pengulangan atau replikasi sebanyak 9 kali setiap perlakuan. Perlakuan yang dilakukan adalah pengomposan menggunakan kompostere aeron dan an-eaerob dengan waktu pengomposan selama 12 Hari. Bahan aktivator yang digunakan dalam proses pengomposan adalah $\mathrm{EM}_{4}$.

Pengukuran parameter yang digunakan dalam penelitian terdiri dari suhu, kelembaban, $\mathrm{pH}$, dilakukan pada hari ke 3,6,9, dan 12 sedangkan parameter bau dan warna dilakukan pengukuran pada hari ke 6 dan 12. Pengukuran suhu menggunakan thermometer, pengujian kelembaban atau kadar air menggunakan basis basah, pengukuran ph menggunakan $\mathrm{Ph}$ meter. Pengamatan bau kompos dilakukan dengan menggunakan indra penciuman, kemudian dilakukan skoring pada bahan. Pengukuran warna bahan dilakukan menggunakan Munsell Soil Color Chart, dengan sistem warna Munsell yang terdiri dari tiga dimensi independent yang dapat diibararatkan seperti silinder tiga dimensi 
sebagai warna tak teratur yang solid : hue, diukur dengan derajat sekitar lingkaran horizontal, chroma, diukur radial keluar dari netral (warna abu-abu) sumbu vertical, dan value, diukur vertical dari 0 (hitam) sampai 10 (putih). Munsell menentukan jarak warna sepanjang dimensi ini dengan mengambil pengukuran dari respon visual manusia.

\section{HASIL}

Tabel 1 menunjukkan temperatur/suhu pada ruang Komposter Aerob rata-rata sebesar $35,68^{\circ} \mathrm{C}$ lebih tinggi dari pada ruang Komposter An-aerob sebesar $32,56^{\circ} \mathrm{C}$. Sehingga mempercepat proses pelayuan dari bahan sampah organik.
Kelembaban udara pada ruang Komposter Aerob rata-rata sebesar 60,80\% lebih rendah dari pada ruang Komposter Anaerob sebesar $68,37 \%$. Sehingga pada ruang di Proses An-aerob lebih lembab kondisinya (tabel 2). Tingkat asam basa pada bahan kompos dengan proses Aerob rata-rata sebesar 7,84 ada kecenderungan sama pada proses An-aerob sebesar 7,78\% (tabel 3).

Tabel 4 menunjukkan bahwa bau atau aroma dari kompos dengan metode an-erob menunjukkan aroma seperti tanah pada hari ke 12 dibandingkan dengan metode eerob dengan bau yang lebih stabil dan terjadi peningkatan bau menyengat pada hari ke 12 .

Tabel 1 Rerata Temperatur (Suhu) pada Ruang Komposter

\begin{tabular}{|c|c|c|c|c|c|c|c|c|c|c|c|}
\hline \multirow[t]{2}{*}{ Pengom-posan } & \multicolumn{9}{|c|}{ Pengulangan Ke- } & \multirow[t]{2}{*}{ Jumlah } & \multirow[t]{2}{*}{ Rerata } \\
\hline & 1 & 2 & 3 & 4 & 5 & 6 & 7 & 8 & 9 & & \\
\hline An-Aerob & 32,08 & 32,77 & 32,62 & 32,92 & 32,46 & 33,00 & 32,69 & 32,15 & 32,31 & 293,00 & 32,56 \\
\hline Aerob & 35,38 & 35,69 & 35,31 & 32,92 & 35,23 & 36,31 & 35,85 & 35,77 & 35,69 & 321,15 & 35,68 \\
\hline
\end{tabular}

Tabel 2 Rerata kelembaban pada Ruang Komposter

\begin{tabular}{lccccccccccc}
\hline Pengom-posan & \multicolumn{1}{c}{ Pengulangan Ke- } & \multicolumn{1}{c}{ Jumlah Rerata } \\
\cline { 2 - 12 } & 1 & 2 & 3 & 4 & 5 & 6 & 7 & 8 & 9 & \\
\hline An-Aerob & 68,15 & 67,85 & 68,62 & 68,38 & 68,46 & 68,69 & 68,23 & 68,23 & 68,69 & 615,30 & 68,37 \\
\hline Aerob & 60,54 & 60,08 & 61,00 & 60,92 & 61,31 & 60,85 & 60,54 & 60,46 & 61,46 & 547,16 & 60,80 \\
\hline
\end{tabular}

Tabel 3 Rerata Tingkat Keasaman pada Bahan Kompos

\begin{tabular}{|c|c|c|c|c|c|c|c|c|c|c|c|}
\hline \multirow[t]{2}{*}{ Pengomposan } & \multicolumn{9}{|c|}{ Pengulangan Ke- } & \multirow[t]{2}{*}{ Jumlah } & \multirow[t]{2}{*}{ Rerata } \\
\hline & 1 & 2 & 3 & 4 & 5 & 6 & 7 & 8 & 9 & & \\
\hline An-Aerob & 7,74 & 7,80 & 7,78 & 7,80 & 7,78 & 7,74 & 7,80 & 7,78 & 7,80 & 70,02 & 7,78 \\
\hline Aerob & 7,83 & 7,86 & 7,85 & 7,82 & 7,82 & 7,86 & 7,85 & 7,83 & 7,86 & 70,58 & 7,84 \\
\hline
\end{tabular}

Tabel 4 Perubahan Bau dan Warna Kompos

\begin{tabular}{llcccc}
\hline \multirow{2}{*}{ Parameter } & \multicolumn{1}{c}{ Perlakuan } & \multicolumn{3}{c}{ Hari } \\
\cline { 3 - 6 } & & $\mathbf{3}$ & $\mathbf{6}$ & $\mathbf{9}$ & $\mathbf{1 2}$ \\
\hline Bau & An-aerob & + & ++ & ++ & +++ \\
Warna & Aerob & + & + & + & ++ \\
& An-aerob & $75 \mathrm{YR}$ & $75 \mathrm{YR}$ & $75 \mathrm{YR}$ & 75 YR \\
& & Brown & Brown & Dark Brown & Dark Brown \\
& Aerob & $75 \mathrm{YR}$ & $75 \mathrm{YR}$ & $75 \mathrm{YR}$ & 75 YR \\
& & Brown & Brown & Brown & Brown \\
\hline Keterangan & & & & &
\end{tabular}

\section{Keterangan: $\quad+\quad=$ Seperti bau aslinya$$
++=\text { Bau menyengat }
$$$$
+++=\text { Bau seperti tanah. }
$$

\section{PEMBAHASAN}

Aroma menyengat pada saat titik puncak pengomposan terjadi karena pada saat proses perombakan bahan melepas gas berupa $\mathrm{NH}_{3}{ }^{+},{ }^{10,11}$ sedangkan bau seperti tanah dikarenakan pada proses pengomposan sudah memasuki fase akhir perombakan bahan kompos. Reaksi ini termasuk reaksi oksidasi yang hasilnya berupa gas amoniak, air dan energi panas sehingga menyebabkan aroma pada perlakuan menjadi menyengat. Maka dapat dikatakan percepatan kompos paling cepat pada perlakuan an-aerob. ${ }^{12,13}$

Hasil skoring warna menunjukkan 
perubahan terjadi pada hari ke 9 pada metode aerob. Pada minggu pertama sampai minggu ke 4 semua perlakuan menunjukkan hue yang sama (hue 7,5 YR), namun memiliki value dan chroma yang berbeda. Hal ini disebabkan aktivator pada kompos dimanfaatkan oleh mikroba secara efektif. Perbedaan warna kompos pada akhir pengamatan menunjukkan tingkat kematangan kompos. Kompos yang dikatakan matang jika memiliki perubahan warna menjadi semakin gelap dan berbau tanah. Perubahan warna kompos disebabkan karena mikrobia pada masing-masing perlakuan berfungsi dengan baik untuk mendekomposisi bahan organik. Nilai value yang semakin kecil akan menunjukkan warna yang semakin gelap dan nilai chroma yang semakin besar menunjukkan warna semakin gelap pula, sehingga jika nilai value semakin kecil dan nilai chroma semakin besar, maka warna yang dihasilkan akan semakin gelap. Perubahan warna pada kompos pada setiap minggunya dari warna hijau atau warna bahan mentahnya menjadi coklat kehitam - hitaman menandakan bahwa kompos sudah menuju matang. Hasil pengamatan warna dari ke lima perlakuan tersebut, perlakuan pada kompos dengan kompos jerami lebih baik dibanding perlakuan lain dalam perubahan warnanya.

Proses Pembuatan Kompos dengan Komposter Anaerob, penguraian bahan organik berlansung tanpa bantuan udara atau oksigen secara maksimal, sehingga proses ini berlangsung secara dingin dan tidak terjadi fluktuasi suhu yang dapat memperlambat penguraian, sedangkan pada proses pembuatan kompos dengan Komposter Aerob, berlangsung dengan suplay udara yang sangat dibutuhkan oleh bakteri pengurai/aerobic sehingga tetap hidup, dan dapat mengurai sampah secara optimal. ${ }^{14,15}$ Semaikin tinggi suhu mendekati 40 pada ruangan dekomposter akan semakin efektifitas bakteri dalam mengurai sampah. Proses penguraian bahan organik dan mikroorganisme lebih optimal pada suhu 30$40^{\circ} \mathrm{C}$ dengan tingkat kelembapan 40$60 \%$. Artinya, tidak terlalu banyak air, tetapi juga tidak terlalu kering. Kelembapan bahan organik membuat mikroorganisme dekomposer cepat berkembang biak sehingga proses penguraian menjadi lebih cepat. Kecepatan penguraian juga berkaitan dengan $\mathrm{pH}$ bahan organik. $\mathrm{pH}$ awal sebaiknya sekitar 6,5 - 8,5 agar hewan pengurai seperti cacing dapat bekerja sama dengan mikroorganisme pengurai.

\section{KESIMPULAN DAN SARAN}

Adanya perbedaan laju pengomposan menggunakan komposter an-aerob dan aerob. Pengoposan an-erob mengalami proses pengomposan lebih cepat dibandingkan dengan pengomposan menggunakan komposter aerob dengan hasil pengoposan terbentuk seperti tanah pada hari ke-12

Pengomposan model komposter an-aerob dapat dikembangakan pada skala umah tangga maupun untuk pengomposan skala sedang. Penelitian selanjutnya dapat mengembangkan parameter lanjutan berupa kandungan unsur hara kompos yang terbentuk dari proses pengomposan menggunakan komposter anaerob maupun aerob.

\section{DAFTAR PUSTAKA}

1. Azmiyah N. Perencanaan Sistem Pengelolaan Sampah Terpadu di Kawasan Pasar Flamboyan Kota Pontianak. J Teknol Lingkung Lahan Basah. 2014;2(1).

2. Madani M. Agenda setting pengelolaan sampah pasar di kota makassar. Otoritas J Ilmu Pemerintah. 2011;1(1).

3. Azkha N. Analisis timbulan, komposisi dan karakteristik sampah di Kota Padang. J Kesehat Masy Andalas. 2006;1(1):14-8.

4. Komala PS, Aziz R, Wahyudi B. Studi Timbulan dan Karakteristik Sampah Kota Padang Panjang. Teknika. 2013;20(1).

5. Qadri U, Wahyuni R, Listiyawati L. Inovasi Manajemen Pengelolaan Sampah Yang Berwawasan Lingkungan Di Kota Pontianak Berbasis Aplikasi. Eksos. 2020;16(2):14460 .

6. Subandriyo S, Anggoro DD, Hadiyanto H. Optimasi pengomposan sampah organik rumah tangga menggunakan kombinasi aktivator EM4 dan Mol terhadap rasio C/N. J Ilmu Lingkung. 2012;10(2):70-5.

7. Widiyaningrum $P$, Lisdiana L. Efektivitas proses pengomposan sampah daun dengan tiga sumber aktivator berbeda. Rekayasa $\mathrm{J}$ Penerapan Teknol dan Pembelajaran. 2015;13(2).

8. Sulistyorini L. Pengelolaan sampah dengan cara menjadikannya kompos. J Kesehat Lingkung. 2005;2(1).

9. Yuniwati M, Padulemba A. Optimasi kondisi proses pembuatan kompos dari sampah organik dengan cara fermentasi menggunakan EM4. J Teknol. 2012;5(2):172-81.

10. Witasari WS, Sa'diyah K, Hidayatulloh M. Pengaruh Jenis Komposter dan Waktu Pengomposan terhadap Pembuatan Pupuk 
Kompos dari Activated Sludge Limbah Industri Bioetanol. J Tek Kim dan Lingkung. 2021;5(1):31-40.

11. Ratnawati R. Adsorpsi Emisi Amonia pada Proses Pengomposan Limbah Padat Rumah Potong Hewan menggunakan Media Kompos Matang. SNHRP. 2019;129-38.

12. Hamdani A. Uji Kemampuan Campuran Trichoderma sp dan Aspergillus sp Sebagai Biodekomposer Terhadap Laju Pengomposan Limbah Jerami Padi. 2015;

13. Setiyo Y. Kajian Tingkat Pencemaran Udara Oleh Gas NH3 dan H2S pada Proses Pengomposan secara aerob. J agrotekno.
2007;13(1):25-8.

14. Pujantoro L. Pengaruh Ketersediaan Oksigen Dan Sistem Aerasi Terhadap Laju Proses Pengomposan dan Kualitas Kompos Berbahan Baku Limbah Pencucian Biji Kakao Terfermentasi, Serasah Daun dan Kotoran Sapi.

15. Syaifuddin MF, Destantyo BH. Pembuatan Pupuk Organik dari Limbah Pertanian dengan Metode Aerob dan Anaerob. Institut Teknologi Sepuluh Nopember; 2018. 